\title{
LOS REYES DE PORTUGAL EN LA FRONTERA \\ CASTELLANO-ARAGONESA (1304)*
}

\section{Maria-Mercedes Costa}

Las relaciones entre Aragón y Castilla habían llegado a un punto de dificil solución. La política de Jaime II había dado un viraje: aún sin abandonar los problemas del Mediterráneo, su interés se volvía de cara a la Península, donde el peligro moro se acrecentaba ante la desunión reinante en Castilla. El interés de Jaime se centraba en dos cuestiones: el Reino de Murcia recién conquistado y el conflicto dinástico de la monarquía castellana. De un lado, Fernando IV, reinante de hecho, a quien se referían los aragoneses como al «qui se dize rey de Castiellaw; del otro, Alfonso de la Cerda, rey titular pero sin reino, con residencia precaria en las tierras sorianas de Deza y Almazán, bajo la protección moral y económica del rey de Aragón. Entre ambos bandos, los hilos de la intriga movidos por los más altos personajes del reino: el infante Enrique, último hijo viviente de Fernando III, hombre de vida turbulenta y de grandes ambiciones; el infante Juan, hijo de Alfonso X y tío de FernandoIV, leal a la Corona según las circunstancias, fallido rey de León, amigo de los portugueses y de Jaime II; Juan Núñez de Lara y la fa-

'Este artículo fue presentado como comunicación al Congreso Luso-Español de Estudios Medievales, Oporto, 1968. 
milia de Haro, los eternos rivales; el infante Juan Manuel, con intereses en Castilla y en Aragón ${ }^{1}$.

Jaime II había buscado la ayuda de su cuñado Dionis, rey de Portugal. Las embajadas habían cruzado en todos los sentidos el territorio ibérico y el resultado, a mediados del año 1303, no podía ser menos satisfactorio. La tregua acordada por Dionís con su yerno Fernando IV y los embajadores aragoneses en Badajoz ${ }^{2}$ quedaba desautorizada por las decisiones tomadas en Ariza por Jaime II y los infantes Enrique y Juan $\mathrm{Manuel}^{3}$. Alfonso de la Cerda, que hubiera salido favorecido por los pactos de Ariza con el reconocimiento efectivo de su real título y con la mano de la infanta Isabel de Castilla, no sólo fue rechazado en ambos puntos por la reina madre, María de Molina, mujer de indiscutible prestigio sin cuyo asenso no prosperaría la idea, sino que se vio atribuir por Jaime II la culpa del fracaso de la tregua, ante el enojado rey Dionis ${ }^{4}$. Los encargados de transmitir las malas noticias fueron los nuncios de la corte portuguesa: Gonzalo Pérez, comendador de Santarem, y Ramón de Montrós, arcediano de Guarda. Ambos circulan repetidas veces entre Dionís, Jaime II y el infante Juan de Castilla, en aquella época amigo de Fernando IV's Dos mujeres estaban tambiến fuertemente interesadas en poner algo de orden en la desorganizada familia peninsular: Isabel de Portugal, buena intercesora entre su esposo y su hermano, y doña Vataza, dama de la reina Constanza de Castilla, cuyo parecer, conocido su afecto por la corte aragonesa, pesaba mucho en los movimientos de los embajadores que nunca dejaban de visitarla ${ }^{6}$.

1 A. Gimenez SOler, Don Juan Manuel, Zaragoza, 1932, pp. 1-27. M. GAIBrols DE Ballesteros, Un episodio de la vida de Maria de Molina, Madrid, 1935, pp. 9-50.

2 ACa (Archivo de la Corona de Aragón), C (Cancillería), registro 334, folios 104 a 106.

3 GIMÉNEZ SOLER, op, cit., p. 21.

${ }^{4}$ ACA, C,r.334,ff. $114 \mathrm{v}, 118 \mathrm{v} ;$ r. 335,ff. 30lv, 309. GIMENEZ SOLER, op. cit., p. 23. GAIBROIS, op. cit., pp.46-47.

${ }^{5}$ ACA,C,r.334,ff. $117-118,120 ;$ r. 335,ff. 308v-309.

6 Vataza era hija de la princesa bizantina Láscara, prima de Jaime II. Había acompañado a Portugal a la infanta Isabel en ocasión de su boda y contrajo matrimonio ella misma con el portugués Martín Gil de Sousa. Ya viuda, se trasladó a Castilla como aya de la infanta portuguesa Constanza, al casarse ésta con Fernando IV. A. MASIX̃, LLa emperatriz de Nicea, Constanza, y las princesas Láscara y Vatazas, Boletin de la Real Academia de Buenas Letras de Barcelona, XX (1947), pp. 145-169. J. Mirex Y SANS, eTres princesas griegas en la corte de Jai- 
Pero los buenos oficios de los nuncios no podian arreglar la situación, que la lejanía de los protagonistas hacía cada vez mas intrincada. Y surgió la idea, para Jaime II ciertamente esperanzadora: era necesario que los reyes se vieran y trataran de palabra la solución de sus diferencias. Jaime seguía viendo en Dionís al único árbitro posible y le dolía que se hubiera molestado por el incumplimiento de la tregua. Procuró apaciguarle y rogó a su hermana Isabel que le persuadiera a celebrar una entrevista ${ }^{7}$. Los soberanos portugueses debían hallarse perplejos ante la actitud de Jaime y le pidieron una explicación clara de sus propósitos. La respuesta fue la siguiente: era preciso un arbitrio, por el que ambos reyes y otra persona, religiosa o seglar, digna de fe, decidirían lo que debía darse en Castilla a los infantes de la Cerda para que éstos renunciaran a sus pretensiones de soberanía; y sobre lo de Murcia trataría Dionís con dos cardenales, arzobispos u obispos, uno aragonés y otro castellano. Y la embajada termina así: «E pareçe otrossi que a firmar estos fechos sean menester vistas». Era el 30 de diciembre de $1303^{8}$.

Sin embargo, Jaime II no debía confiar demasiado en la buena marcha de esos asuntos. En el fondo seguía reconociendo el mejor derecho de Alfonso al trono castellano, pero el temor al enemigo sarraceno dominaba tal vez en él sobre cualquier otro sentimiento. Y esta fue una de las más poderosas razones que le movieron a buscar el apoyo que creyó más eficaz: el papa. Encargó a sus nuncios en la Corte Romana, fray Bernat Peregrí, prior de la Orden de Predicadores en Aragón, Vidal de Vilanova y Guillem de Lacera, que acudieran a los cardenales de su mayor confianza, Mateo Rosso Orsini y

me II de Aragóns, Revue Hispanique, XV (1906), pp. 668-720. Idem., «Nuevos documentos de las tres princesas griegas», Revue Hispanique, XIX (1908), pp. 112-134. J. BAUCELIS 1 REIG, «L'expansió catalana, fou vehicle d'irradiació culturals, Segundo Congreso Intermacional de Estudios sobre las culturas del Mediterräneo Occidental. Trabajos leídos en Barcelona, Barcelona, 1978, pp. 247-269. 7 ACA, C, r. 334, FF. 120, 120 v; r. 335, F. 309, GIMENEz SOLER, op, cit., pp. 24-25. posiblemente la idea de las vistas la había tenido ya la misma Isabel; al saber por Montrós que Fernando IV deseaba ver a Dionís vio una ocasión para poner paz entre Aragón y Castilla si se conseguía que Jaime II tomara parte en la entrevista, y así envió a éste al arcediano para manifestarle su buen deseo ya a mediados de diciembre. D. J. Dormer, Discursos varios de Historia, Zaragoza, 1683, p. 104: publica el texto de la carta de Isabel a Jaime, documento que en la fecha de esa publicación se hallaba en el Archivo de la Diputación de Zaragoza.

8 ACA, C, r, 334, ff, $120 \mathrm{v}-122$. 
Landulfo Brancaccio, y con gran sigilo les explicaran lo que ocurría, pidiéndoles consejo. Jaime deseaba que el papa tomara la dirección de los hechos, en nombre de la lucha contra los infieles, y que, dadas las treguas convenientes, enviara un legado a España para tratar la paz entre los reyes. Parecía que no había de costar mucho convencer a Fernando IV, ya que buen número de sus nobles, si él no se avenía a ceder una parte de Castilla a Alfonso, estaba dispuesto a abandonarle. No obstante, no quería Jaime que se conocieran sus movimientos cerca del pontífice. Los cardenales deberian plantear el asunto como si hubiera surgido de ellos la idea. Por otro lado les ayudaría el prior de Santa Cristina, procurador del rey en la Corte Romana, quien ponderaría el malestar existente en la Península y el gran mal que representaba la guerra de los moros. Otra carta a jugar era la del rey de Nápoles, aunque en segundo término; mejor que lo llevaran todo los cardenales solos, pero si el rey Carlos y su hijo se hallaban en Roma podía explicárseles también la situación, cargando el acento en el peligro moro; y advirtiéndoles que si algo hacían por Jaime no debía saberlo nadie más que los pocos interesados; a los demás tenían que darles a entender que se encontraban allí sólo para asuntos relacionados con Cerdeña?

Dos meses más tarde, a mediados de marzo de 1304, Jaime reclamaba a los nuncios que le informaran, aunque fuera brevemente, sobre si habian hecho o esperaban hacer lo que tenían encargado, para que él supiera a qué atenerse ${ }^{10}$. Con todo, fue solamente el día 14 de marzo cuando los nuncios llegaron a la presencia del papa, quien les acogió muy favorablemente. Le habló Peregrí con gran secreto de los asuntos del rey, pero se encontró con que el prior de Santa Cristina ya había informado al pontífice y al consistorio en enero y se sabía que el cardenal Pedro Hispano, amigo de los castellanos, había dicho que la paz era imposible si Jaime II quería tener todo el Reino de Murcia. Luego los negocios habian quedado interrumpidos por las fiestas de Semana Santa y por la marcha del Papa a Perusa, a donde le acompañó el mismo Peregrí mientras los otros nuncios iban a Nápoles ${ }^{11}$. Las cuestiones que debían ser secretas tu. vieron que plantearse luego ante el Colegio Cardenalicio por volun-

9 ACA, C, r. 334, ff. 189-190. V. SALABERT, Cerdena y la expansión medirerránea de la Corona de Aragón, Madrid, 1956, I, p. 257; II, pp. 104-105 (fragmento del documento 72).

10 Aca, C, r. 334, f. 190v. Salavert, op. cit., I, p. 259; II, p. 119, doc. 86.

11 SAlaverT, op. cit., 1, pp. 250, 260. H. FinKe, Acta Aragonensia, 1, Berlín, 1908 , docs. $53,109,111$ y 112 . 


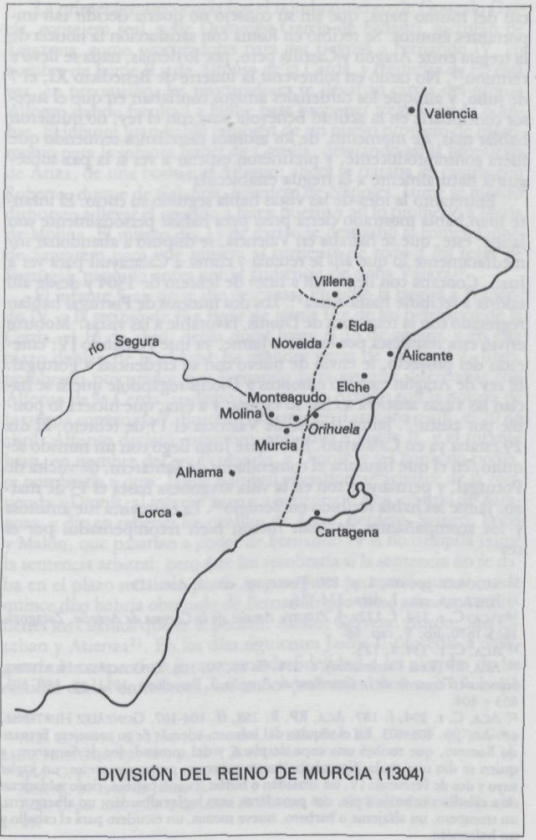


tad del mismo papa, que sin su consejo no quería decidir tan importantes asuntos. Se recibió en Roma con satisfacción la noticia de la tregua entre Aragón y Castilla pero, por lo demás, nada se llevó a término ${ }^{12}$. No tardó en sobrevenir la muerte de Benedicto XI, el 7 de julio, y aunque los cardenales amigos confiaban en que el sucesor continuaría en la actitud benévola para con el rey, no quisieron hablar más, de momento, de los asuntos castellanos temiendo que fuera contraproducente, y prefirieron esperar a ver si la paz subseguiría naturalmente a la tregua establecida ${ }^{13}$.

Entretanto la idea de las vistas había seguido su curso. El infante Juan había mostrado cierta prisa para hablar personalmente con Jaime; éste, que se hallaba en Valencia, se dispuso a abandonar inmediatamente lo que allí le retenía y correr a Calatayud para ver a Juan. Contaba con llegar allí a fines de febrero de 1304 y desde alli saldria a recibirle hasta Ariza ${ }^{14}$. Los dos nuncios de Portugal habían regresado con la respuesta de Dionís, favorable a las vistas. Montrós envió esta respuesta por escrito a Jaime, ya que Fernando IV, enterado del proyecto, le envió de nuevo con su credencial a Portugal. El rey de Aragón escribió entonces a Dionís rogándole que si se hacían las vistas asisriera a ellas su esposa; y a ésta, que hiciera lo posible por asistir ${ }^{15}$. Jaime II salió de Valencia el 15 de febrero. El día 29 estaba ya en Calatayud. El infante Juan llegó con un nutrido séquito, en el que figuraba el comendador de Santarem, de vuelta de Portugal, y permanecieron en la villa aragonesa hasta el 13 de marzo. Jaime les había recibido en Berdejo ${ }^{16}$. La entrevista fue amistosa y los acompañantes de Juan fueron bien recompensados por el rey ${ }^{17}$.

12 SalaverT, op. cit., I, p. 250. FinKE, op cit., I, doc. 113.

is FINKE, op, cit., 1, docs. 114-116.

14 ACA, C, r. 334, f. 122v. J. Zurrta, Anales de la Corona de Aragón, Zaragoza, 1665-1670, lib. V, cap. 66.

is ACA, C, r. 334, f. 123.

16 ACA, RP (Real Patrimonio), r. 268, ff. 89, 99, 108. E. GonzÃIfZ HurteBise, Libros de Tesorería de la Casa Real de Aragón, I, Barcelona, 1911, pp. 386, 395. 403 y 404.

17 ACA, C, r. 294, f. 187. ACA, RP, R. 268, ff. 104-107. GONZĀLEZ HURTEBISE, op. cit., pp. 401-403. En el séquito del infante, además de su consejero Fernando Romero, que recibió una copa de plata, y del comendador de Santarem, a quien se dio una mula, figuraban: cuatro porteros, nueve camareros, un juglar suyo y dos de Fernando IV, un albardán o bufón, cuatro correos, cinco soldaderas de a caballo y ocho de a pie, dos panaderas, otro juglar albardán, un alberguero. un trompero, un alfajeme o barbero, nueve mozos, un escudero para el caballo y un halconero. 
La primera consecuencia fue el nombramiento de Gonzalo García, consejero real, y de Domingo García de Echauri, sacristán de Tarazona, como procuradores para dar treguas a Fernando IV, en nombre de Jaime II y de Alfonso de la Cerda, y recibirlas de él; esta vez, en precaución, los procuradores se llevaban cartas del propio Alfonso dando facultad a Jaime para proponer treguas en su nombre. El infante Juan habló también de un nuevo proyecto de matrimonio para la infanta Isabel de Castilla, desviando así la propuesta de Ariza, de una boda con Alfonso; ahora se trataba de casarla con Roberto, duque de Calabria, heredero de Nápoles. Jaime se mostró dispuesto a llevar el negocio a buen puerto y así lo prometió a María de Molina. El mismo día 13 de marzo se despachó al comendadorde Santarem para que pusiera al corriente de todo a los reyes de Portugal, pasando antes por la audiencia de doña Vataza ${ }^{18}$.

El infante Juan no se dio descanso. Propuso la tregua a Fernando IV, y la recibió de él a favor de Jaime II y de los hermanos de la Cerda, el 15 de abril; debía durar hasta el 15 de agosto, y en este plazo debían de celebrarse las grandes vistas de los reyes ${ }^{19}$. Juan, nombrado procurador por Fernando para arreglar diferencias con Alfonso de la Cerda, se dispuso a volver a Aragón con la noticia de la tregua convenida ${ }^{20}$. Encontró a Jaime en Tarazona y allí, el 20 de abril, Alfonso declaró compromisario suyo a Jaime II, y el infante Juan, en nombre del rey Fernando, a Dionís; y si Dionís no podia, se nombraría a otro. Jaime nombró oficialmente árbitros de la contienda a Dionís, al infante Juan y a Jimeno de Ahe, obispo de Zaragoza, y dio en rehenes los castillos de Ariza, Berdejo, Somed, Borja y Malón, que pasarían a poder de Fernando IV si no cumplía Jaime la sentencia arbitral; pero éste los recobraría si la sentencia no se daba en el plazo señalado por la tregua. Juan prometió que antes de quince días habría obtenido de Fernando que diese asimismo en rehenes los castillos que se le pedían: Alfaro, Cervera, Autón, San Esteban y Atienza ${ }^{21}$. En los días siguientes Jaime II procedió a desligar de los respectivos juramentos de fidelidad a los alcaides de los castillos dados en rehenes, los cuales prestaron homenaje al obispo

18 ACA, C, r. 334, ff. 123v-124v; r. 294, f. 187. ACA, RP, r. 268, f. 107v. GoN ZÄLEZ HURTEBISE, op. cit., p. 403 . ZURITA, loc, cit.

19 ACA, C. p. (pergamino) 1997 de Jaime II. ZURITA, loc. cit.

20 ACA C. p. 1998 de Jaime II.

21 ACA, C, ps. 2000 y 2002 de Jaime II. ZURTTA, loc, cit. GIMÉNEZ SOLER, op. cit., p. 25 . 
de Zaragoza, uno de los árbitros, actuando en nombre de los tres ${ }^{22}$. El infante Juan, en Roa, obtuvo también de Fernando IV los rehenes y la promesa de respetarlos, así como el juramento del compromiso, lo que comunicó por escrito a Jaime II $^{23}$.

El objetivo siguiente era Portugal, y hacia allí se encaminaron los nuncios Echauri i Montrós y el infante Juan en persona, mientras Fernando IV marchaba a Burgos para resolver las cuestiones que tenía con Diego y Juan Alfonso de $\mathrm{Haro}^{24}$. El rey de Aragón, por su parte, comunicó a sus nuncios en Roma lo acordado en Tarazona y reiteró la demanda de consejo ${ }^{25}$. El infante Juan llegó a Guarda pensando encontrar allí al rey Dionís. Pero un suceso imprevisto, la muerte del conde Juan Alfonso, lo había impedido. Se encontraron finalmente en Coimbra, en donde estaban ya los embajadores. Dionís se mostró de acuerdo con los compromisos y accedió a llevar consigo a la reina. Proyectó salir de Guarda el día de san Juan y, en vista de ello, el infante recomendó a Jaime II que enviara al obispo de Zaragoza y a los alcaides de los cinco castillos para que se encontraran con la comitiva portuguesa por los alrededores de Salamanca; Juan llevaría consigo a los alcaides castellanos y así Dionís vería que la cuestión se presentaba correctamente ${ }^{26}$.

El rey Dionís sentía cierta impaciencia por ver a Jaime y opinaba que el lugar señalado para las vistas quedaban muy lejos para él. En aquellas fechas, 10 de junio, el punto exacto no estaba aún bien determinado. Fernando IV había propuesto que se celebraran en Ägreda y Tarazona; pero alguien había hablado de Molina y Daroca, y sonó también el nombre de Berdejo. De todos modos serían en la frontera castellano-aragonesa. El infante Juan, la reina Isabel y los portugueses-temían sin duda que la impaciencia de Dionís agrandara los obstáculos y le hiciera desistir de la empresa. Por eso enviaron a Aragón a Martín Pérez, criado de la reina, así como a los embajadores ya mencionados, con el ruego que el mismo Juan ha-

22 ACA, C, ps. 2003, 2004, 2008, 2009 y 2010 de Jaime II.

23 ACA, C, p. 2007 de Jaime II; c. (cartas reales) de Jaime II, 2215.

24 ACA, C, r. 334, f. 125 Memorias del rey Don Fernando IV de Castilla, publica. das por A. de Benavides, Madrid, 1860, p. 130. ZururA, Loc. cit.

25 ACA, C, r. 334, f. 191. SALAVERT, op. cit., I, p. 260: II, p. 121, doc. 89.

26 ACA, C, c. 2258 de Jaime II. Juan Alfonso de Meneses, conde de Barcellos y señor de Alburquerque, era el padre de Teresa Martins, casada con Alfonso Sánchez, hijo natural del rey Dionís, del cual dicho conde fue mayordomo mayor. (Antonio Caetano DE Sousa, Historia Genealógica da Casa Real Portugueza, Lisboa 1735; ed. Coimbra, 1946, 1, p. 150). 
cía por escrito desde Viseu: que Jaime II emprendiera el viaje y llegara lo más lejos que pudiera, dentro de Castilla, para encontrar a Dionís. Se pedía también a su consejero Gonzalo García que hiciera lo posible para que el rey se decidiera, ya que Dionís saldría de Sabugal por san Juan y en diez o quince dias estaría en San Esteban de Gormaz ${ }^{27}$. Antes que a Jaime, el sacristán de Tarazona vio a Alfonso de la Cerda y le explicó todo lo ocurrido en Portugal; según él, Dionís llegaría cerca de Medina del Campo el 5 de julio ${ }^{28}$.

Jaime contestó rápidamente a los mensajes, contento de la venida de los reyes, y desechó el lugar de Berdejo para las vistas ya que era demasiado pequeño y con pocos medios para la cantidad de gente prevista. Juan, que ya estaba en Burgos el 28 de junio, le instó otra vez para que fuera a instalar sus tiendas en San Esteban de Gormaz en espera de la llegada de los portugueses, y para que enviara a éstos al obispo de Zaragoza y a Gonzalo García. El infante Juan Manuel, que también estaba en Burgos, comunicó asimismo a Jaime la llegada de Juan, $y$, unos días más tarde, a instancia suya, por creer, según él mismo decía, que así servía mejor al rey de Aragón, Fernando IV dejó el asunto de los Haro en manos de Juan Núñez y de Alfonso, hijo del infante Juan, y se dispuso a prepararse para las vistas ${ }^{29}$. Mientras el infante Juan salía de nuevo en dirección a Portugal para recibir a los reyes, Jaime II proyectaba salir de Zaragoza, lo más tarde el 15 de julio, para dirigirse a las tierras de Soria ${ }^{30}$. En efecto, el día 16 estaba en Alagón y el 18, sábado, en Pozuel ${ }^{31}$. El obispo de Zaragoza y Gonzalo García, que ya habían marchado a Castilla, le informaron del viaje de los portugueses. Jaime II contaba con que éstos llegarían a Huerta el viernes siguiente: por ello ordenó a su canciller Ramón Despont, obispo de Valencia, que reuniera el jueves en Zaragoza a todos los barones y caballeros que debían asistir a las vistas, y que fueran a juntarse con el soberano en las cercanías de Monreal de Ariza donde parecía que tendrían lugar aquéllas ${ }^{32}$. Fernando IV había ido a instalarse en Agreda, desde donde, el primero de agosto, nombró procuradores a Ferrench Gómez, chanciller y notario mayor del Reino de Toledo, y a Diego García, chanciller del sello de la puridad y mayordomo de la reina

27 ACA, C, ds. 2246, 2256 y 2261 de Jaime II.

28 ACA, C, cs. 2228 y 2248 de Jaime II.

29 ACA, C, cs. 2246,2226 y 2235 de Jaime II.

30 ACA, C, 2205 de Jaime II; r. 294, f. 198; r. 258, f. 144v.

31 ACA. C, r. 254 , ff. $74,108-108 v$ y $111 ;$ c. 2234 de Jaime II

32 ACA, C, c. 2234 de Jaime II. 
Constanza, para que oyeran y aprobaran por él la sentencia arbitral sobre Murcia; y al infante Juan para oir y aprobar la referente a Alfonso de la Cerda ${ }^{33}$.

Las vistas estaban preparadas en lo político. Pero en lo material no habían sido menos laboriosos los preparativos. En aquellas épocas de frecuentes guerras y de cortes casi siempre itinerantes, unas vistas representaban siempre un acontecimiento social de primer orden. Los personajes que se entrevistaban iban siempre rodeados de un numeroso y brillante séquito y tenía lugar una sucesión de banquetes y fiestas. Las vistas de 1304 habían de tener una importancia excepcional, no sólo por las graves cuestiones que en ellas se debatirían sino por lo que representaría el encuentro de tantos reyes y altos personajes en aquellos parajes fronterizos.

Jaime II, que actuaba de anfitrión, quiso ponerse al elevado nivel de las circunstancias y desde principios de mayo estaba planeando los actos y pensando en todos los detalles. Su primera preocupación fue disponer de dinero suficiente. Para ello ordenó al tesorero Pedro Böll que fuera a Cataluña en busca de fondos, y a Pere Meseguer que le entregara todo lo que tenía cobrado para la corte y todo lo que desde entonces recibiera, sin pasar por la escribanía de ración ${ }^{34}$. Al mismo tiempo se preparaban los víveres. En un principio se mandó que hicieran una considerable entrega los súbditos de la Orden del Hospital en Zaragoza, Samper de Calanda y Caspe; es posible que hubiera alguna objeción por parte de la Orden, porque se suspendió el mandamiento hasta que el lugarteniente del castellán de Amposta hubiese hablado con el rey. Con todo, se sabe que los comendadores de Mallén y Grisenich entregaron trigo y avena ${ }^{35}$. El rey envió a varios servidores a adquirir provisiones: Esteve de Roda, Guillem y Bartomeu de Riudovelles, Pere March, etc. Hubo pueblos que quedaron en difícil situación, agravada por la esterilidad de aquel año; así Tahuste, al que tuvo que darse la seguridad de que durante un año no se le exigirían más donativos de $\operatorname{pan}^{36}$. Además de cereales, los pueblos dieron gran número de cabezas de ganado y de aves de corral. Y lo dieron en calidad de préstamo, cuyo importe tardarían aún en cobrar ya que hubo de asignárseles sobre los diversos impuestos y subsidios que se pagaban en Aragón.

33 ACA, C, ps. 2057 y 2058 de Jaime II.

34 ACA, C, r, 294, f. 185.

35 ACA, C, c. 2170 de Jaime II; r. 258, f. 156.

36 ACA, C, r. 258, f. 159 v. 


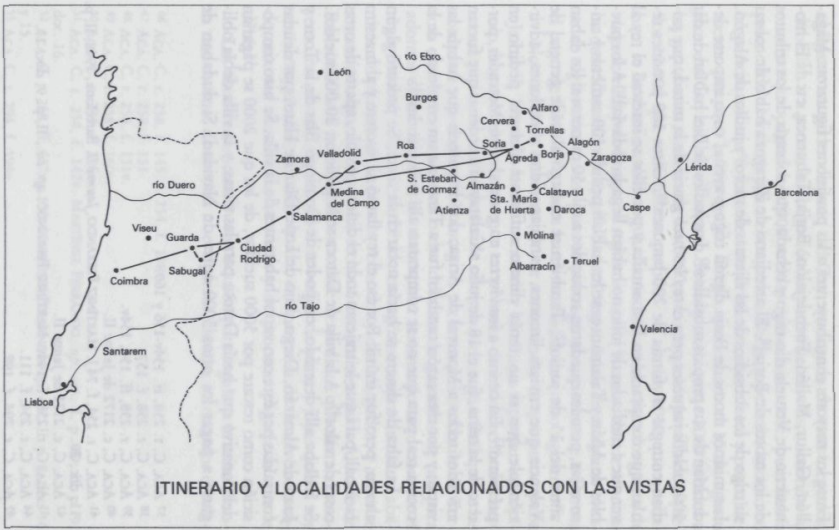


Entre los mayores contribuyentes a las provisiones figuraron: Magallón, Gallur, Mallén, Fuendejalón, Borja, Tabuenca, etc. ${ }^{37} \mathrm{El}$ monasterio de Veruela dio trigo y cebada, que cobraría de los tributos de los moros de Borja ${ }^{38}$. El arcediano de Zaragoza había de cobrar su trigo de los subsidios de las aljamas de moros y judíos de Alagón. Los mismos moros de Borja dieron trigo y avena, cuyo importe deducirían de sus propios subsidios ${ }^{39}$. Los judíos de Biel habían de das 500 sueldos jaqueses pero el rey les hizo gracia de la mitad, que podían entregar en forma de 200 jamones ${ }^{40}$. Otros 100 jamones tenían que comprarse en la montaña y por ellos se interesó el rey al ver que a mediados de julio no habían llegado todavía ${ }^{41}$. A los pueblos de Añón y Talamantes se les habían pedido 100 carneros y cin. co vacas, pero les quedaron reducidos a sólo 50 carneros si los daban antes del 15 de junio ${ }^{42}$. También se encargó al baile general de Valencia que enviara limones, naranjas, cidras y melones, advirtiéndole que si no tenía dinero suficiente debería pedirlo en préstamo ${ }^{43}$. En cuanto a los víveres en general, Pere Mercader, portero de la reina, fue el 18 de julio a Calatayud a ordenar que fueran enviados todos a Monreal de Ariza, donde parecía que habría las vistas; y por esta razón también fue a Tarazona un empleado de la cocina real para que no se compraran allí más viandas ${ }^{44}$.

La falta de dinero se hacía notar en la corte. Se procuró algún ahorro, pero fue inútil. Por eso el rey llamó al tesorero y al maestro racional, para que le trajeran todo el dinero posible, aparte de otras cosas de valor ${ }^{45}$. A la villa de Daroca se le pidieron 20.000 sueldos. Se hallaba alli detenido, en poder de Domingo Blas de la Torre y Juan de Almazán, Diego, hijo de Lope Díaz de Haro, por deudas contraídas por éste con varios habitantes de la villa. Se hizo composición como rescate por 5000 sueldos, de los que 2000 se pagarían del donativo que hacía Daroca para las vistas; y la villa debía obligarse a pagas los otros 3000 antes de Navidad. Si dudaban de

37 ACA, C, r. 258 , ff, $154 \mathrm{v}-156$ y 160.

38 ACA, C, r, 258, f. 157.

39 ACA, C, r. 258, ff. 154, 154v.

$40 \mathrm{ACA}, \mathrm{C}$, c. 2172 de Jaime II.

41 ACA, C, r. 254, f. 74 J. Martinez Ferrando, Jawme II, Barcelona, 1948, II, p. 11, doc. 20.

42 ACA, C, c. 2171 de Jaime II.

43 ACa, C, , 258, f. L44u. Marttinez Ferrando, op. git., II, p. 9, doc. 17.

44 ACA, C, r. 254, f. 111.

4 ACA, C, r. 294, f. 198. 
obligarse en poder de Juan del Gay, encargado de estos negocios, deberían ir a prestar la obligación en poder del rey. Este ordenó a su tesorero que pagara los 2000 sueldos inmediatamente, pues había prometido al infante Juan entregarle a Diego y pensaba hacerlo en las próximas vistas ${ }^{46}$. La orden no debía de tener efecto y probablemente tampoco la entrega de Diego, por cuanto el 15 de agosto Juan del Gay recibía el encargo de dar por el rescate 5000 sueldos a los guardianes, sacados de los 6000 que aún debía la villa de aquellos 20.000 que se le habían pedido ${ }^{47}$. Y de los 1000 que queda. ban, se les dieron a dichos guardianes 300 sueldos para los gastos de viaje de ellos y de Diego en seguimiento de la corte, donde se trataba de la liberación de éste ${ }^{48}$. Sin embargo, debía de arreglarse el caso de algún otro modo, pues se prorrogó posteriormente a Daroca el pago de los 6000 sueldos hasta mediados de enero siguiente 49 .

No era sólo la manutención de sus invitados lo que preocupaba a Jaime II. También la indumentaria y las alhajas suponían un capítulo de gastos. Jaime supo que un peletero de Lérida tenía dos hermosas pieles de cuellos de ánade silvestre y encargó a Boill que se las comprara y las trajera ${ }^{50}$. Y con gran premura pidió al baile de Tortosa que le comprara una o dos docenas de granadas de oro para adornos de sus vestidos, a un mercader tartamudo cuyo nombre el rey ignoraba ${ }^{51}$. Al baile de Lérida encargó la compra de cuatro abanicos de plumas de pavo, dos redondos y dos alargados, y como se retrasaran algunos días se los reclamó con insistencia ${ }^{52}$. Al baile de Barcelona tuvo que hacerle otra clase de pedido: que diera al tesorero una silla de montar y varias vasijas de plata y joyas que el rey tenía empeñadas, por una deuda, con promesa de devolvérselo todo una vez terminadas las vistas y de procurar pagarle lo que le debía $^{53}$.

Las vistas fueron una buena ocasión para regalar a la reina Blanca una corona: de oro, en nueve piezas, llevaba incrustados 6 bala-

46 ACA, C, r. 258, f. $145 ;$ r, 254, f. $108 \mathrm{v}$.

47 ACA, C, r. 258, f. 151 .

48 ACA, C, r. 258, f. $151 \mathrm{v}$.

49 ACA, C, r. 258, f. $160 \mathrm{y}$.

50 ACA, C, r. 294, f. 196r.

51 ACA, C, r. 258, f. 142v. Martinez Ferrando, op. cit., 1, p. 69; II, p. 9. doc, 16 .

52. ACA, C, r. 258, ff. 127v y 132. MARTINEZ FerRando, op. cit., II, p. 8, docs 14 y 15 .

53 ACA, C, r. 294, f. 194v 
jes grandes y 16 pequeños, 2 esmeraldas grandes y 8 pequeñas, 2 zafiros grandes y 12 pequeños y 8 perlas grandes; además iba decorada con numerosas piedras de pequeño tamaño: 96 esmeraldas, 104 balajes, de los que sólo faltaba uno, y 112 perlas. También el pequeño infante Alfonso recibió una bocina de marfil con anillos de plata y un cordón de seda roja. Es curioso que no se hable de regalos al infante primogénito. La reina estrenó unas riendas de seda redondas para su caballo; el rey, otras riendas semejantes y una cabezada hecha de hilo de oro y seda. También tuvo el rey un nuevo mandil como peinador, de hilo de oro tejido con seda azul y roja, con 14 escudos en hilo de oro y plata, llevando el signo real y las águilas de Sicilia, y cerrado al cuello con dos cordones. Y hasta a su perro alano se le hizo un collar de seda con el signo del castillo y el león. Por otra parte, se hicieron para la capilla dos paños de oro con imágenes del crucifijo. Y para el comedor, dos almohadones de cordobán destinados a los que han de estar arrodillados junto a la mesa real ${ }^{54}$.

Otro gasto notable representó la asistencia de los súbditos principales de la Corona, cuyos problemas particulares hubo de resolver el rey para asegurarse su presencia. Empezando por Alfonso de la Cerda, que le envió a pedir ayuda para prepararse decorosamente. Jaime dijo al enviado que volviera dentro de ocho o diez días y así lo hizo, reiterando Alfonso la petición, que hizo extensiva a la reina. El rey dijo a Alfonso que fuera a Tarazona y es de suponer que le ayudó según él esperaba 55 . Se concedió a varios caballeros una moratoria de deudas hasta después de las vistas: así a Jimeno Cornel, a Atón de Lesuno, a Jimeno Pérez de Pina (a quien se le embargó una cantidad de trigo como garantía), etc. ${ }^{56} \mathrm{~A}$ otros hubo de procurárseles dinero constante: el pago de una mesnadería a Jimeno López de Gurrea, 1000 sueldos a Pedro Ferriz de Peña, 100 a Juan de Rocafort que volvía de Castilla, 170 a Guerau de Aguiló, que no hubiera podido salir de Zaragoza sin ellos $^{57}$. Hubo quienes pudieron adelantar el dinero pero necesitaron auxilio posterior: Gombaldo de Entenza tuvo que obligar su lugar de Oso (entre Fraga y

${ }^{54}$ ACA., C, r. 258, f. 152v. Martinez Ferrando, op. cit., I, p. 72; II, p. 12, doc. 21.

Aunque dado a conocer por dicho autor el texto del documento, por creerlo de interés lo publicamos de nuevo al final del presente artículo.

"s ACA, C, cs. 2228, 2236 y 2227 de Jaime II; r. 254, f. 111.

56 ACA, C, r. 133 , ff. $11 \mathrm{v}, 29 \mathrm{v}$ y 39.

57 ACA, C, r. 258, f. 144v; r. 254, ff, 109 (2 docs.) y 108. 
Monzón) y por ello se le dieron 5000 sueldos; 3000 recibió Artal de Luna $^{58}$. Algunos, en fin, excusaron su asistencia, como Galcerán de Anglesola que recibió el aviso el viernes anterior a san Juan y calculó que no tenía tiempo para prepararse como cumplía a su personalidad, por lo que declinó el honor de la invitación ${ }^{59}$.

No es posible dar ni siquiera el número aproximado de las personas que se congregaron en la frontera en los días de las grandes vistas, y mucho menos sus nombres. Tan sólo por los firmantes de la sentencia arbitral se sabe que además de los dos procuradores de Fernando IV había los obispos de Lisboa (Juan Martínez de Soalhaes), de Valencia (Ramón Despont) y de Huesca (Martín Pérez Azlor), Juan Ozores, maestre de Santiago, García López, maestre de Calatrava, y muchos nobles de las tres cortes peninsulares ${ }^{60}$. También había representantes de las ciudades: Teruel, por ejemplo, envió a seis prohombres ${ }^{61}$. La familia real aragonesa estuvo presente en su totalidad. Con un subsidio de las aldeas de Daroca para la casa del infante Jaime, el primogénito, se procuró la asistencia de éste y de sus hermanos, aún de muy corta edad ${ }^{62}$. De Castilla vinieron con el rey a Ágreda, con certeza, su esposa Constanza, su madre María, su hermano Pedro, los infantes Juan y Juan Manuel y doña Vataza. Y de Portugal, con los reyes, su hijo Alfonso. Dice Zurita que los portugueses trajeron consigo un millar de caballeros. Se les ofrecieron castillos para las etapas de su viaje, pero Dionís no quiso aceptarlos y resolvió su hospedaje por medio de campamentos ${ }^{63}$.

Fernando IV recibió a los portugueses en Medina del Campo (Zurita dice que los reyes se vieron en Roa) y juntos se dirigieron a Soria. Allí llegó la reina madre, María de Molina, que en un principio quería excusar su asistencia, y toda la familia real castellana permaneció instalada en Ảgreda mientras Dionís pasaba a Tarazona, donde le recibió Jaime. Finalmente se había escogido para las vistas el lugar de Torrellas, ede gran deleyte y frescura», en las faldas del

38 ACA, C, r. 294, ff. 199v y 200.

59 ACA, C, c. 2260 de Jaime II.

60 ACA, C, p. 2062 de Jaime II.

61 ACA, C, c, 2237 de Jaime II.

$62 \mathrm{ACA}, \mathrm{C}$, r. $258, \mathrm{f} .145 \mathrm{v}$. Ocho años tendría el infante Jaime, cinco Alfonso, poco más que éste María, cuatro Constanza, tres Juan, y de muy poca edad sería Isabel, la última entonces nacida (J. MARTINEZ FERRANDO, Els fills de Jaume II, Barcelona, 1950, pp. 25, 61, 89, 103, 119 y 137).

63 ZURITA, loc. cit. 
Moncayo ${ }^{64}$. Allí, el sábado, 8 de agosto, se pronunció la sentencia arbitral que fue aprobada por Jaime y por los dos procuradores de Fernando IV. Por ella se dividía el Reino de Murcia, quedando para Aragón los lugares y villas de Cartagena, Guardamar, Alicante, Elche y su puerto, Elda, Novelda, Orihuela y sus términos, y la tierra entre el río Segura y Valencia por el término de Villena, excepto Murcia y Molina que quedaban para Castilla junto con Montagudo, Lorca, Alhama, etc. Villena permanecía en la propiedad de Juan Manuel bajo el señorío de Jaime II. Los habitantes de aquellas tierras serían libres de marchar o de quedarse en ellas y habría un intercambio de prisioneros y rehenes. $\mathrm{Y}$ se daba un plazo de tres días para que el acuerdo recibiera todas las confirmaciones reales ${ }^{65}$.

Asimismo se dio la sentencia sobre Alfonso de la Cerda: se le concedian numerosos lugares en Castilla por valor de 400.000 morabetines, libres de toda sujeción al rey y a sus descendientes. Fernando lo respetaría y daría rehenes. Y se fijaba el plazo hasta el día de san Martín para que Alfonso devolviera a Fernando todos los lugares que le tenía ocupados hasta ahora y renunciara a titularse rey; de lo contrario se le anularía la concesión ${ }^{66}$.

Al día siguiente, domingo, los reyes se reúnen en Campillo con Fernando IV y firman un pacto de amistad mutua. Fernando ratifica la sentencia y los infantes Juan, Pedro y Juan Manuel prestan homenaje por ella a Jaime II. El día 10 están todos en Ägreda y allí Fernando jura a Alfonso de la Cerda que si los lugares que le ha dado en Castilla no suman de renta 400.000 morabetines, él le dará otras posesiones hasta que las rentas sean suficientes. También absuelve de fidelidad a sus vasallos de los lugares de Murcia que pasan a Jaime II y concede remisión general a sus vasallos de nueva adquisición, confirmándoles fueros y privilegios ${ }^{67}$. Prometen guardar todo lo pactado los maestres de Santiago, Calatrava y Alcántara ante Alfonso, obispo de Astorga, y Gonzalo García, consejero real aragonés ${ }^{68}$. En Ágreda los reyes van a visitar a María de Molina en su posada; las reinas de Aragón y Portugal se reúnen a comer con la

64 Memorias, p. 133.

65 ACA. C, p. 2062 de Jaime II. Memorias, p. 133. ZURITA, loc, cit. DORMer, op. cit. p. 135. GIMENEZ SOLER, op. cit., Pp. 25-26.

66 ACA, C, c. 1736 de Jaime II (borrador de la sentehcia). ZURrrA, loc. cit.

67 AcA, C, p. 2063 de Jaime II; c. 1815 de Jaime II (borrador del pacto). Memorias, p. 133. DORMER, op. cit., p. 141. ZURTTA loc. cit.

68 ACA, C, ps. 2066, 2064 y 2065 de Jaime II. Memorias, p. 133. Dormer, op.cit., p. 142. ZURITA, loc. cit. 
reina Constanza, mientras que sus esposos son huéspedes de Fernando. Otro día ellos comen con la reina Maria, y al día siguiente se trasladan todos a Tarazona donde permanecen dos días más ${ }^{69}$. El día 13, aún en Ảgreda, Fernando pone en libertad a los presos y rehenes de Aragón ${ }^{70}$. En Tarazona acuerda con Jaime la forma de entregar el uno al otro los lugares que les corresponden por la sentencia. Aquel mismo día se ordena ya pregonar la paz recién hecha con Castilla, en Calatayud, Daroca, Teruel, Albarracín y la ciudad y Reino de Valencia ${ }^{71}$. Jaime H, contento del buen fin que parecian tener sus problemas, recompensó inmediatamente a uno de los artífices de las vistas, Ramón de Montrós, doblândole los 500 sueldos que le había dado sobre la cena anual del comendador del Hospital de Zaragoza, con otros 500 sueldos vitalicios: 300 sobre la cena de la aljama de Teruel y 200 sobre la de Daroca ${ }^{72}$.

El domingo siguiente, día 16, en el convento de frailes menores de Tarazona, Alfonso de la Cerda aprueba ante Jaime y Dionís la sentencia que a él se refiere ${ }^{73}$. Probablemente aquel día se despiden los reyes.

Jaime se queda en Tarazona hasta el día 17 y se ocupa en dar disposiciones sobre Murcia y Lorca, que dejarían de ser suyas ${ }^{74}$. El dia 18 está en Gallur, donde sigue dando órdenes a los de Elche ${ }^{75}$. Y el 21 está ya en Zaragoza y permanece allí varios días; desde allí comunica las últimas e importantes noticias a los nuncios en Roma con encargo de transmitirlas a los cardenales amigos, a quienes también ha escrito sin especificarles la forma de la paz. Escribe también al rey de Nápoles sin grandes detalles de las vistas ${ }^{76}$. Expide gran número de debitorios a los pueblos que han contribuido con víveres para las mismas ${ }^{77}$; da orden de pago de 2000 sueldos al sacristán de Tarazona por su salario y gastos de su servicio en la corte, y de recibirse en cuenta al merino de Zaragoza los gastos del palafrén blanco que el rey le dejó antes de salir de la ciudad para ir a las vistas ${ }^{78}$.

69 Memorias, p. 135. ZURTrA, loc, cit.

$70 \mathrm{AcA}$, C, p. 2068 de Jaime II. ZURITA, loc, cit.

71 ACA, C, p. 2067 de Jaime II; c. 2045 de Jaime II.

72 ACA, C, r. 202 , ff. $168-168 \mathrm{v}$.

73 ACA, C, c. 2259 de Jaime II.

74 ACA, C, cs. 2045 2, 2045 b, 2045 c, de Jaime II.

75 ACA C. es. $2045 \mathrm{~d}, 2045$ e, de Jaime II.

76 ACA, C, r. 334, ff. 191v-193. SALAVERT, op. cit., I, p. 260; II, p. 141 , doc. 104.

77 ACA, C, r. 258, ff. 154-160.

78 ACA, C, r. 294 , f. $202 ;$ r. 258, f. $160 \mathrm{v}$. 
Antes de volver a sus respectivas tierras, y según se acostumbraba en semejantes ocasiones, los visitantes recibieron del rey Jaime ricos obsequios. Poseemos la descripción de tales presentes ${ }^{79}$. El rey Dionís recibió un cuchillo que llevaba una piedra roja en el extremo del mango y cuatro abrazaderas de plata donde se veían los escudos de Aragón con las águilas; otro cuchillo con mango de marfil que tenía esculpidas seis cabezas femeninas; tres cuchillos de mesa con mangos de jaspe; un cinto ancho, de seda verde con orla de seda roja y plateada y adornos de metal; un zurrón de perlas blancas, rojas y azules, con dibujo de flores, cerrado con un gran botón de perlas que terminaba en cinco zafiros pequeños; dos docenas de pihuelas para atar las patas de los azores y halcones; un tablero de ajedrez de marfil y ébano; dos piezas de brial de Chipre; un barril de nácar con tres aros, cuatro pies y el gollete de plata dorada, colgado de una cinta violeta con adornos plateados; y un vaso de plata con el interior y el borde dorados y decoraciones en nácar.

A la reina Isabel se le regalaron dos pares de guantes, unos con la insignia del rey de Aragón y las águilas y otros de tejido de oro y seda con forro de tela roja ${ }^{80}$; dos paños de terciopelo de seda con el signo real; una prenda para cubrir la cabeza, tejida de oro y seda por ambas caras; un relicario de Agnus Dei de plata, cincelado; una copa de cristal con el pie y el borde de plata dorada; y un jarro de nácar con el pie, cuello, asa y gollete de dicho metal.

Al infante Alfonso de Portugal se le dio un bordón con tres abrazaderas de plata dorada decoradas con flores; un cuchillo con mango de coral adornado de plata; un cinto rojo y azul con adornos plateados; una bocina de marfil con cordón de seda de colores; un zurrón de seda verde con dibujos de figuras humanas, forrado de tela roja y con un gran botón de perlas; un mandil para afeitar, de lino, con trabajos en hilo de oro y de seda negra, verde y roja, cerrado en el escote con tres botones de hilo de oro y dos de seda negra; y dos piezas de brial de Chipre. La infanta de Portugal recibió otra pieza de la misma tela.

La reina Constanza de Castilla, un salero decorado con un ramo de plata que tenía en el centro la figura de una víbora con varias piedras azules, rojas y verdes; y tres cuchillos, dos con mangos de jaspe y uno con mango de cristal y abrazaderas de plata.

79 ACA, C, r. 258, f. 152v. Martinez Ferrando, Jaume II, I, p. 72; II, p. 12 , doc. 21. (Vid. nota núm. 54).

80 Martinez FERRANDO, Jaume II, 1, p. 71. 
Al rey Fernando se le regaló un peine de marfil y una prenda para la cabeza, de seda, con botones de plata dorada.

Al infante Juan, un cinto de seda adornado de plata, con el signo real y con hebilla cincelada. Al infante Pedro, otro cinto de seda roja y azul con adornos de plata dorada. Y a doña Vataza, una copa de plata dorada por dentro y por fuera.

La comitiva de los reyes castellanos y de los portugueses marchó de Âgreda a Valladolid, donde pasaron cinco días. Allí se presentó a ellos Fernando de la Cerda, que se hizo vasallo de Fernando IV. Este le recibió de buen grado y le hizo muchas concesiones; en su opinión de entonces, el de la Cerda sera muy buen hombres. Fernando IV hubiera acompañado a Dionís hasta más lejos, pero éste no se lo permitió. Entonces quiso esperar a los procuradores de Alfonso de la Cerda para entregarles las tierras y lugares prometidos, pero viendo que tardaban se marchó a León, llevado por su afición a la caza. Dejó en Valladolid a su madre; la teina Constanza probablemente se fue a Toro ${ }^{81}$. Dionís y su séquito continuaron hacia Portugal. El arcediano Ramón de Montrós les acompañó hasta Ciudad Rodrigo y de alli le hicieron regresar a la corte castellana, donde tenía que quedarse de momento por voluntad de Jaime II y de su hermana Isabel, recomendándole que comunicara a Jaime el buen viaje que habían tenido. El día 7 de septiembre los reyes entraron en su país y el 8 estaban en Guarda, donde encontraron al resto de su familia ${ }^{82}$.

El hecho fue que Montrós había vivido en la corte portuguesa una experiencia desagradable. Juan Simón, merino mayor del rey de Portugal y canciller de la reina, parece que intrigaba contra ésta. Isabel, en Âgreda, se quejó a su hermano Jaime, quien le contestó: *Ermana, façet vos el vuestro, que Johar Simon sempre fara el seu com home de vil logar e pos que nos de la amor del rey no podemos partir, pasat con el al mellor que podades como fazestes ata quis. Ella hubiera seguido este consejo, pero hubo de saber y presenciar otras cosas que tal vez hubieran modificado la actitud de Jaime si las hubiera conocido antes. En Castilla, Simón pugnó por alejar de la casa real a doña Vataza, que estuvo ausente sólo ocho días. En Salamanca no hacía más que acusar a Jaime II de haber promovido disensiones en Tarazona, con placer de la reina Isabel. Y ante ésta, en su mansión, desafió a Montrós diciéndole que por su culpa él

81 ACA, C, c. 12542 de Jaime II. Memorias, p. 135. ZuRrTA, loc, cit.

82 ACA, C, cs. 12541,12542 y 12551 de Jaime II. 
había perdido la merced de la soberana; Montrós le respondió que no se lo dijera dos veces, pero Simón repetidas veces le llamó traidor y falso y le amenazó de muerte, ante ouras personas; y en cuanto a la reina, dijo que ya estaban fuera de Aragón y que no se haría lo que ella quería. Isabel se disgustó mucho y rogó al obispo de Lis. boa que interviniera para que ese hombre no siguiera faltándole al respeto. Llamó al rey, que estaba ya informado por el propio obispo, y le pidió que vengara la ofensa; si no, ella escribiría a los reyes parientes suyos y a otros amigos para que lo hicieran. Y mandó a Montrós y a Martín Pérez que escribieran a Jaime para que éste interpusiera sus buenos oficios a fin de que Dionis castigara al culpable. Dionís reconoció que Simón había obrado muy mal, con lo que la corte le consideró ya perdido ${ }^{83}$. Jaime II entró de lleno en el asunto y el primero de octubre, desde Tortosa, escribió a Montrós lamentando lo ocurrido y comunicándole que intervendría como se le había pedido. Y en efecto, procuró tranquilizar a Isabel y pidió a Dionís que castigara a Simón como tenía merecido; además, rogó al obispo de Lisboa y a Martín Gil, mayordomo mayor del infante Alfonso, que hicieran ver a su rey la gravedad de los hechos y le aconsejaran el castigo del culpable ${ }^{84}$. Este intentó defenderse: envió a Martín Pérez a la corte aragonesa pidiendo a Jaime II que no creyera lo que de él se decía. No sabemos si fue castigado Simón y en qué forma lo fue. Parece que tuvo que recapacitar y reformar su conducta: en una carta a Jaime II de fecha 31 de marzo, que hemos de suponer de 1305, se muestra sumiso y dispuesto a servirle, a él y a su reina. Jaime le había escrito que si servía bien a ésta, él no le tendría ningún rencor; y Simón recuerda que, ya en Tarazona, Jaime le recomendó ese buen servicio y reconoce que obra mal si no sigue su consejo, porque la reina le trata con toda benevolencia ${ }^{85}$.

Tal vez terminara aquí ese enojoso asunto que enturbió la euforia de las pasadas vistas. Ya podían ocuparse los reyes en terminar también lo que en las vistas sólo se había apuntado: la división de Murcia, cuya frontera no se señalaría hasta 1305 tras laboriosos trabajos; y la entrega de lo estipulado a Alfonso de la Cerda ${ }^{86}$. Entretanto, los reyes estaban satisfechos. Podrian venir nuevas disensiones, pero, de momento, Isabel había triunfado en su deseo de paz,

83 ACA, C. cs. 12542 y 12551 de Jaime II.

84 ACA, C, r. 335, ff. $312 \mathrm{v}-313 \mathrm{v}$.

83 ACA, C, cs. 1961 y 11106 de Jaime II.

86 GIMENEZ SOLFR, op. cit., pp. 26-27. 


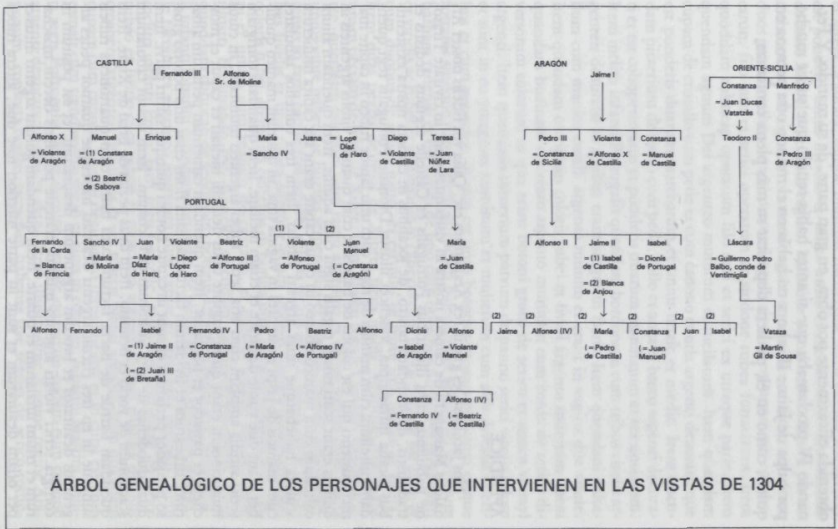


obtenida eficazmente por obra, en gran parte, de su marido. Y Fernando IV proclamaba que si antes había tenido que sufrir mucho por culpa de Jaime II, ahora no había en el mundo otra persona en quien, como en él, pudiera depositar su más plena confianza.

\section{APÉNDICE}

Nos Jacobus Dei gracia rex Aragonum etc. Quia vos fidelis noster Arnaldus Massagerii de camera nostra in vistis quas nunc in civitate Tirasone habuimus cum illustribus Portugalis et Castelle regibus dedistis et tradidistis, de mandato nostro, de jocalibus in camera nostra existentibus jocalia infrascripta, videlicet illustri Dionisio Portugalis regi quendam cultellum cum manico de roart cum uno lapide rubeo in capite manici existenti qui est coloris de balays et cum quatuor virolis argenteis in quibus erant scuti nostri regalis signi cum aquilis. Item quendam alium coltellum cum manico ebureo in cuius capite erant sex capita mulierum sculpta habebatque duas argenti virolas. Item tres cultellos tabulares cum manicis de jaspi existentes in vagina una, in quorum manico quolibet erant due virole deaurate et etiam niellate. Item quandam corrigiam serici viridis amplam cum orla serici rubei argenteo munitam, in cuius municionem erant quinquaginte unus dentelli niellati et caput et moscheta et passador et peniador. Item quendam carnerium perlarum albarum, rubearum et lividarum factum ad sina floris cum uno botono grosso penjador perlarum et sunt in capite botoni quinque saffiri parvi. Item duas duodenas de gitz austorum et falconum. Item unum tabularium scachorum de vorio et benusio. Item duas pezias de brial de Xipre. Item quoddam barrile de nacra factum cum barris cum quartonetis rubeis suntque in eo tres circuli argenti deaurati habetque quatuor pedes argenteos deauratos et brocum argenteum deauratum, et est positum in corrigia serici violati argento munita eratque ponderis decem marcharum et trium unziarum et quarte. Item quendam gotum argenti intus et per orlam deauratum et sunt in parte inferioti rose due, altera rubea 
et altera deaurata, estque munitus nacro cum barris et cum scachetis et est ponderis unius marche et unius unzie et medie. Item illustrissime domine Issabel Portugalis regine, karissime sorori nostre, unum par cirothecarum ad signum nostrum regale et aquilarum factarum. Item duos pannos velluts de serico nostri regalis signi. Item unum par cirothecarum filo auri et serici operatum ac sindone rubea forratarum. Item quoddam cubricap operatum filo auri et serici ex utraque parte. Item quendam agnum Dei argenteo munitum et niellatum. Item quandam cupam de cristallo cum pede et cum canono et orla argenti deaurati, que est ponderis duarum marcharum et unius unzie et medie. Item quendam pitxerium de nacro cum pede, collo et ança et broco argenti deaurati et est cohopertoratus et ponderis duarum marcharum et sex unciarum. Item inclito infanti Portugalis quendam bordonum cum tribus virolis argenteis deauratis in quibus erant singnum floris. Item quendam cultellum cum manico coralli argento munito et erant in vagina due virole. Item quandam corrigiam coloris rubei et lividi argento munitam. Item quandam buzinam ebuream argento munitam cum corda de serico diversorum colorum in qua erant botoni grossi de serico et unum versayl argenti. Item quendam carnerium parvum de panno serici viridis piloso et sunt in eo ymagines hominum et mulierum cum aliis diversis operibus et cum penjador, in quo est unus botonus grossus perlarum estque forratus sindone rubea. Item quendam balendreuet aptum ad servicium barbam radendi et est panni de lino cum operibus fili auri et serici nigri et viridis ac rubei et adjungitur in cabezio cum tribus botonis fili aurei et cum duobus de serico nigro, et est talis ex parte una qualis ex altera. Item duas pezias de brial de Xipre. Item inclite infantisse Portugalis unam peciam de brial de Xipre. Item illustri regine Castelle, nepoti nostre, quendam salerium cum ramo argenteo et est in medio rami forma unius vipre habetque linguas serpentinas et sunt in circuitu lingue existentis in rami capite tres lapides coloris viridis infixe cum duobus lapidibus lividis et una rubea suntque etiam ibidem lapides pendentes duo coloris rubei. Item tres cultellos in vagina una, duos cum manicis de jaspi et unum cum manico de cristallo, et habent virolas argenti. Item illustri Ferdinando regi Castelle quendam pectinem ebureum. Item quoddam cubricap de serico cum botonis argenteis deauratis. Item nobili infanti Johanni quandam corrigiam de serico ad signum nostrum regale factam et argenteo munitam cum capite et moscheta niellatis. Item inclito infanti Petro, fatri regis Castelle, quandam corrigiam de serico rubeo et livido cum capite et moscheta argenti et cum triginta duabus crochetis argenteis deauratis et sex rosetis planis argenti. Item quandam cupam cum copono argenti deauratam intus et extra et in cupa est unus esmalt cum signo nostro regali et alius in copono, Johanni Martini, militi regis Portugalis. Item domine Betasse quandam cupam cum copono argenti deauratam intus et extra. Item illustrissime domine regine Aragonum, consorti nostre, quasdam habenas sive regnas de serico rotun- 
das. Item eidem domine regine, consorti nostre, quandam coronam auream que est novem pessiarum suntque in ea infixi sive encastats sex balays grossi et sexdecim parvi et duo maragdi grossi et octo parvi et duo saffiri grossi et duodecim parvi et octo perle grosse, et tota corona est munita perlis parvis et balays parvis, sunt etiam ibi, ultra predictos, nonaginta sex maragdi parvi et balays parvi sunt centum et quatuor suntque perle minute centum et duodecim, et de ipsa corona nil defficit nisi unus balaxet parvus. Item fratri Petro Alegre, capellano nostro, ad opus capelle nostre duos pannos aureos in quibus sunt imagines Crucifixi. Item inclito Alfonso, nato nostro, quandam buzinam ebuream cum virolis argenteis et cum cordono de serico rubeo. Item Salvatori de Turolio, cavellaricio nostro, ad opus nostri quasdam habenas de serico rotundas et quasdam capzanas filo auri et serici operatas. Item Parchasio Luppi, barbitonsori nostro, ad opus nostri quendam balendreuet aptum ad servicium pectinandi factum cum operibus fili auri et serici lividi et rubei et sunt in eo quatuordecim scuti fili auri et argenti ad nostrum regale signum et ad signum aquilarum et adjungitur in cabezio cum duobus cordonis. Item fuit amissus unus exelonus in camera regine Castelle. Item fuerunt facti duo coxini de duobus corriis cordovani ad opus illius qui ad mensam nostram flexis genibus habet stare. Item tradidistis Salvatori de Turolio prelibato ad opus unius alani nostri unum collarium serico operatum ad signum castri et leonis. Idcirco tradicionem per vos de suprascriptis jocalibus factam ut superius est distinctum gratam habemus ac etiam acceptamus. Et in huius rei testimonium presentem litteram vobis fieri jussimus nostro sigillo sigillatam.

Datum Tirasone $\mathrm{XVI}^{\circ}$ kalendas septembris anno predicto $\left[\mathrm{M}^{\circ}\right.$ $\mathrm{CCC}^{\circ}$ quarto].

Guillelmus Augustini mandato regis facto per Petrum de Monello.

ACA, C. F, 258, f. $152 \mathrm{v}-153 \mathrm{v}$. 